\title{
Effects of cognitive styles on 2D drafting and design performance in digital media
}

\author{
Sule Tasli Pektas
}

Published online: 4 July 2008

(C) Springer Science+Business Media B.V. 2008

\begin{abstract}
This paper investigates the interactions between design students' cognitive styles, as measured by Riding's Cognitive Styles Analysis, and performance in 2D drafting and design tasks in digital media. An empirical research revealed that Imager students outperformed Verbalisers in both drafting and creativity scores. Wholist-Analytic cognitive style dimension was found to be independent from drafting and design performance. The study suggests that examining the cognitive styles of students in Computer Aided Design (CAD) education deserves further attention and may facilitate for improvements in learning processes.
\end{abstract}

Keywords Cognitive styles - Creativity - Drafting and design performance · Design education · Digital design media

\section{Introduction}

The utilization of digital tools is increasingly dominating design education in parallel with the developments in professional practice. There is an ever-growing body of literature on the subject; however, it was observed that most of the existing studies have merely focused on relatively technical issues such as experimental uses of new media, tool development, or implementation of related courses. The wide socio-cultural and behavioural contexts of Computer Aided Design (CAD) education have remained to be ignored (Pektas and Erkip 2006). Tweed (2001) recognized that CAD systems often embodied a stereotypical view of designers while individual differences of users were rarely considered. It is widely accepted that there may be some characteristics of individuals that affect their behaviours in digital design tasks, but such interactions have not been studied systematically, yet (Tweed 2001).

\section{S. T. Pektas $(\square)$}

Faculty of Art, Design and Architecture, Department of Interior Architecture and Environmental Design, Bilkent University, Ankara 06800, Turkey

e-mail: tasli@bilkent.edu.tr 
One interesting topic in this respect is the effects of designers' cognitive styles on their design performance in digital media. Cognitive styles refer to individuals' typical or habitual modes of encoding, storing, and processing information (Witkin et al. 1971; Messick 1984; Riding and Cheema 1991; Curry 1983). They are regarded as distinct personality characteristics which are innate, relatively permanent and mainly independent of intelligence (Riding and Rayner 1998; Armstrong 2000; Riding 2000a). The relationship between digital tools and cognitive processes of designers is still a growing area of study. Several studies suggested that the use of computers in design entailed different cognitive processes compared to the traditional design process in terms of parameters such as total number of cognitive actions (Bilda and Demirkan 2003), synthesis strategies (Stones and Cassidy 2007), or ideation moments (Jonson 2005). However, the interactions between digital design media and cognitive-personality styles of design students are still unclear. Considering the pervasiveness of digital applications in design education, insights into such interactions would facilitate for developing teaching strategies and course designs that are well-adopted to individual differences of learners. This in turn, has the potential to improve design education.

Within this framework, the present study aimed to investigate the effects of particular cognitive styles on design students' performance in drafting and design processes in digital media. An empirical survey examined cognitive style profiles of novice design students, engaged them in a domain-specific design task in which computer was the design medium, and evaluated their products at three stages of the design process with field experts in terms of creativity and technical quality of the products. The particular research questions of the study are presented below:

1. Is there any relationship between design students' cognitive styles and design performance in digital media?

2. Is there any relationship between design students' cognitive styles and $2 \mathrm{D}$ drafting performance in digital media?

3. Do interactions between cognitive styles and performance in design tasks change through three stages of the design process; namely, conceptual/early design, design development, and final design?

This paper reports the findings of the study. Implications of the results and the limitations of the study are also discussed and suggestions are made for further research.

\section{Cognitive styles}

The term "cognitive style" has been widely used by educational theorists for the past 60 years. Some researchers have used this term as a synonym of "learning style" assuming that they represent the same construct (Riding and Rayner 1997). Curry (1983) proposed a model for all cognitive and learning style measures which grouped them into three strata drawing an analogy with the layers of an onion. In this model, the outermost layer of the onion, the most observable style is instructional/learning preference. Instructional preference refers to the choice of one learning situation or condition over another. It is considered as the least stable style since it is modifiable by learning environments. The second layer of the hypothetical onion model is the information processing/learning style. This is defined as the way(s) each individual perceives and processes new information. Curry (1983) discusses that information processing styles are more stable than instructional preferences, but they are still subject to change due to the environment. The core of the onion, the "cognitive-personality" level is 
understood to be the most stable style, and fundamental to and interactive with the operation of the other levels in the model (Curry 1983). This paper adopts Curry's conceptualization of cognitive styles. Since cognitive styles were assumed to be independent from educational processes, the findings of this paper could be more appropriate for generalization compared to that of similar studies which utilize learning style measures.

Although numerous cognitive style labels have been mentioned in the literature, some authors recognized that they had often referred to the same dimensions (Messick 1984; Miller 1987). Riding and Cheema (1991) attempted to unite existing approaches and claimed that different cognitive style definitions could be clustered around two bipolar axis: Wholist-Analytic and Verbaliser-Imager. These two dimensions are assumed to be independent from each other. The Wholist-Analytic (WA) dimension describes individuals' tendency to process information either as a whole or through dividing into parts. It is assumed that Analytic individuals prefer to abstract things from their environments and to process information in a sequential manner, while Wholists are more likely to see "the whole picture" and to use intuition. Riding and Cheema (1991) discussed that several earlier cognitive style definitions such as Field dependence-Independence (Witkin et al. 1971), Holist-Serialist (Pask 1972) and Diverging-Converging (Hudson 1966) represented the different conceptions of this dimension. The Verbaliser-Imager (VI) dimension, on the other hand, refers to individuals' inclination toward coding information either verbally or pictorially. Imagers are considered as individuals "who think" in terms of mental pictures as opposed to Verbalisers "who think" in terms of words. Paivio's (1971) Individual Differences Questionnaire and Richardson's (1977) Verbaliser-Visualiser Questionnaire belong to Verbal-Imagery cognitive style family (Riding and Cheema 1991).

\section{Interactions between cognitive styles and task performance}

It was acknowledged that cognitive styles might affect learning preferences as well as problem solving styles and task performance (Riding 2000a). Previous studies investigated the relationships between cognitive styles and performance in several fields and many indicated that the levels of performance are significantly different for people with different cognitive styles (Riding and Cheema 1991; Armstrong 2000; Martinsen and Kaufmann 2000). Furthermore, the relationship between cognitive styles and task performance was shown to depend on the nature of task and individuals tended to perform better in tasks consonant with their cognitive styles (Riding 2000a). On the WA dimension Analytic individuals preferred structured approaches to decision-making, applied systematic methods of investigation, and attained better results in tasks requiring step-by-step execution. Wholist individuals, on the other hand, inclined to rely on impulsive synthesis and lateral reasoning and worked best on tasks favouring a holistic approach (Riding 2000b; Armstrong 2000; Martinsen and Kaufman 2000). Having reviewed the results of several studies analyzing the relationships between VI cognitive styles and task performance, Riding and Cheema (1991) concluded that Verbalisers were likely to perform best in verbal tasks, while Imagers in imaginal ones.

Several works of design theory suggested that an individual's cognitive style might be related to his/her performance in design tasks. In design methods tradition, design has been conceived as an "ill-defined" problem solving activity involving a number of sub-activities such as analysis, synthesis and evaluation (Cross 1993). All of these activities require intensive information processing whether as wholes or through abstraction, in images or in words. Many design theorists suggested that design, being a holistic process, requires 
consideration of various and sometimes conflicting goals in a simultaneous rather than a sequential manner (Archer 1984; Schon 1985; Cross 1990; Lawson 1997). Furthermore, studies on design process frequently reported that "intuitive" design behaviour is the most effective and relevant to the intrinsic nature of design (Cross 2004). All of these arguments suggest that Wholists might be more successful in design tasks compared to the other end of the WA spectrum: Analytics. The connection between the VI cognitive style dimension and designing may also be predicted, since imagining is regarded as crucial for the generation of new design ideas (Schon 1983; Finke 1990; Lawson 1997; Goldschmidt and Smolkov 2006). Thus, we may expect that Imagers would outperform Verbalisers in design and drafting tasks.

There are only a few empirical analyses of the interrelationships between cognitive styles and attainment in design tasks. On the contrary with the assumptions of design theorists, existing studies indicated that Analytics performed better than Wholists in design tasks (Roberts 2006; Atkinson 2006). Roberts (2006) studied the relationships between the WA cognitive styles of Cognitive Styles Analysis (CSA) and the design studio performance of architectural design undergraduates at particular stages of architectural education and observed that Analytics achieved better than Wholists in the early years in architectural education, but the difference disappeared at the later years of education. Atkinson (2006) investigated teacher trainees' performance in design and technology tasks and found that Analytics were the most successful group on the WA dimension, although the differences between the groups were small. Atkinson (2006) included also the VI cognitive styles in the analysis and reported that Imagers were the most successful cognitive style group both on the VI dimension and among the all cognitive style groups as described by CSA.

To the best of the author's knowledge, associations between cognitive styles of designers and performance in design tasks in digital media have not been empirically analyzed yet. Therefore, hypotheses can be formulated only on the basis of general aspects of digital design methods. Modelling with digital design tools requires both procedural and declarative modes of thinking i.e. mentally breaking an object into simple objects and executing a series of commands (Hamade et al. 2007). This coincides with the "draw and modify" working principle of the current commercial CAD software i.e. complex forms are derived by modifying simpler forms (Coyne 2002; Bilda and Demirkan 2003). These suggest that drafting and design with conventional CAD programs may favour Analytics who tend to abstract objects from the environment and prefer to work sequentially. Considering the visual nature of such tools, one may also expect that being close to the Imager end of the VI spectrum would also be advantageous.

\section{Methodology}

Research setting and participants

The participants were sophomore students of the Department of Interior Architecture and Environmental Design, in Bilkent University. The research was conducted in a onesemester introductory-level obligatory CAD course. In this course, students acquire basic CAD skills and toward the end of the semester, they are expected to utilize these skills in a simple design project in which computer is the design medium. 2D AutoCAD was utilized for these purposes, since it has been the most widely used CAD application in the building design industry in Turkey. In fact, despite the developments in 3D modelling, 2D media still maintains its vital position in building design education. In a recent survey of CAD 
instructors (Garcia et al. 2005), 2D drawing was considered as the most important aspect of $\mathrm{CAD}$ followed by dimensioning and layers, 3D modelling ranked fourth.

The sample consisted of all students who took the course in one semester. A total of 46 students, whose ages ranged from 18 to 24 , participated the study. The mean age was 20.28 and the standard deviation was 1.59. There were 34 females (74\%) and 12 males (26\%). A survey conducted at the beginning of the semester revealed that the students were quite experienced in computers. The average period of using computers was 6.5 years for the sample. However, most of the students $(93.5 \%)$ had no experience with computer aided design tools. Only a few students reported that they had ever used a CAD tool before.

\section{Procedures}

The experiment spanned the last three weeks of the semester. The students worked individually and it was ensured that they got the same instructions throughout the process. In the first week, the students received the design brief which specified design requirements of a small-scale architectural design project in detail (Fig. 1). They were asked to design an entrance building in a university campus. Main function of the space was controlling

\section{Design Brief}

You are asked to design a small building at the main gate of a university campus. Main function of the space is controlling the entrance to and exit from the university. Two security staff will occupy the space. They will check university identity cards of people and of vehicles coming to the university. Other requirements are below.

Basic elements to include:

- A WC cabinet including a WC and a sink

- A kitchenette including a sink and a small cooker

- A desk and some means of storage for identity cards

- Chairs or other devices for sitting

- Lighting fixtures for general and task lighting
You should also:

- Ensure that the building conveys a symbolic meaning representing the identity of the university.

- Explain your design concept by writing it in a separate sheet.

- Provide visibility of the roads at the two sides of the building.

- Specify structural system of the building (columns, beams, load bearing walls, etc.).

- Specify all the materials used with their dimensions and renderings.

- Pay attention to ergonomics (health, safety, comfort).

- Differentiate public - private areas.

- Try to include as much information as possible about your design.

Fig. 1 Design brief

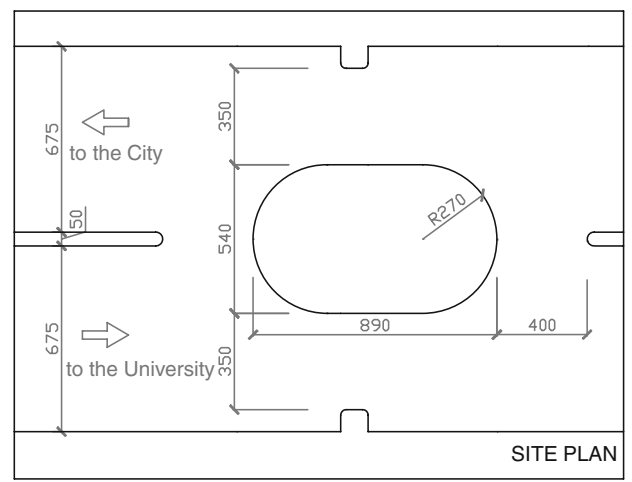


entrance to and exit from the university. It was assumed that two members of security staff would occupy the space and they would check the identity cards of the vehicles approaching the gate. The brief included basic private requirements of the staff (such as a WC, a kitchenette and some means of sitting) besides the main public activity. It was also requested that the building should have a symbolic meaning representing the identity of the university. The brief consisted of a balanced mixture of visual and verbal material as well as that of creativity and technical/functionality requirements as is common in sophomore level design studios.

In the first meeting, the subjects produced conceptual designs using AutoCAD and Architectural Desktop during three course hours. At the end of the session, they submitted their works in AutoCAD file format. During the following week, the students were allowed to develop their designs and in the second meeting, they discussed their designs with the course instructor. The same instructor conducted all of the classes in order to prevent bias. The design works were also collected in that day. During the last week, students finalized their designs and at the end of the week, they submitted the final works. Student works produced at the three stages of the process were evaluated by the field experts as explained in the following section.

Measures

\section{Cognitive styles}

Although there are several instruments to measure different aspects of cognitive styles, Cognitive Styles Analysis (CSA) developed by Riding (1991) was used in this research, since it synthesizes various approaches to cognitive styles construct and its reliability and validity were established well via empirical research. CSA is a computer presented and self-administered instrument which identifies cognitive styles of individuals on the Wholist-Analytic and Verbaliser-Imager dimensions. In fact, each style dimension represents a continuum and subsequent labels are only attached to ranges on a dimension for convenience (Riding and Cheema 1991). Every member of the sample completed the CSA in the manner prescribed in the CSA administration documentation (Riding 1991). Participants were informed about their cognitive styles at the end of the study.

\section{Design and drafting performance}

Three expert judges, composed of design faculty, were asked to evaluate all of the design solutions in three stages following Amabile's (1996) Consensual Assessment Technique (CAT). CAT is a well-established technique to appraise creativity in art and design tasks and was utilized in several studies previously (Jeffries 2007; Meneely and Portillo 2005; Christiaans 2002). In line with CAT, the judges were instructed to rate the creativity and the technical quality of the students' works relative to one another and to work independently. Each judge was supplied with written instructions and an evaluation sheet to record their responses. In accordance with Amabile's protocol on the consensual assessment of products, the judges were requested to use their own subjective definition of creativity. Technical quality was defined as the extent to which designs satisfy technical/functionality requirements as suggested by Christiaans (2002). The assessments were based on a scale of 1-5 where 1 indicating low performance and 5 indicating high performance. Figure 2 illustrates two example solutions to the design task. Drafting performance was evaluated 

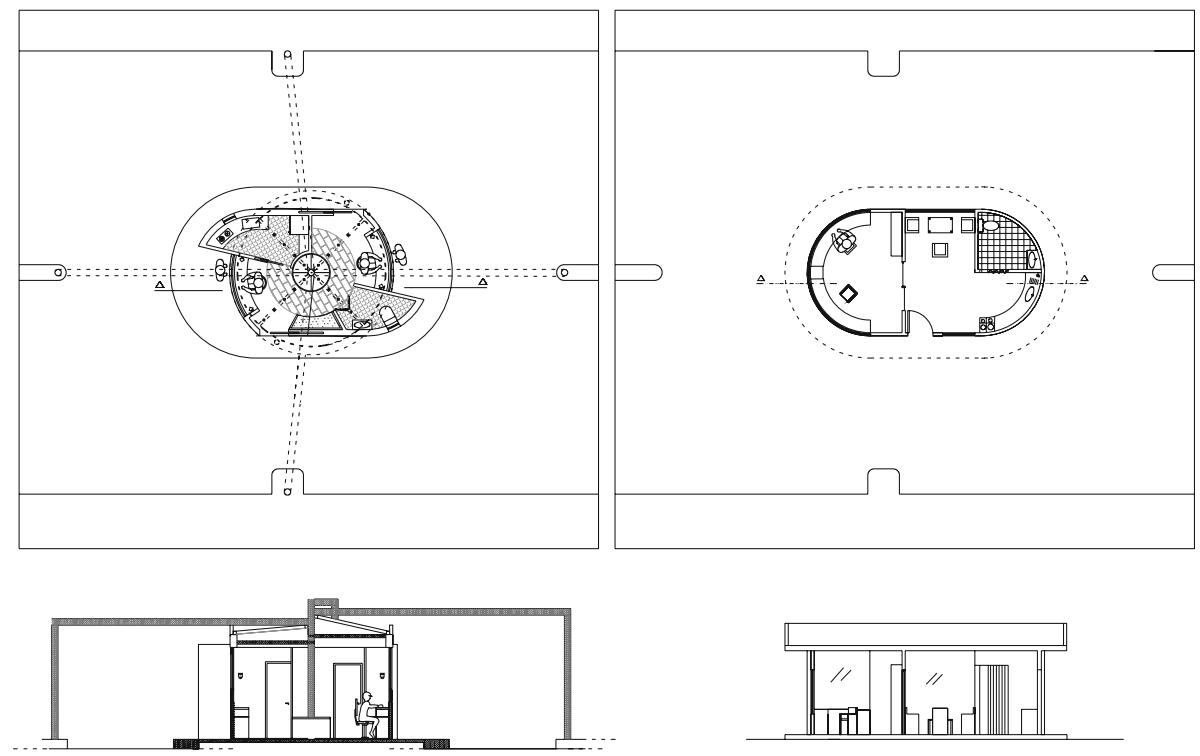

Fig. 2 A high (a) and a low (b) scoring creative solution to the design task

by a drafting exam which was given as a requirement of the course before the experiment. The drafting performance scores were assessed in a range between 0 and 100 and they indicated how accurately and completely students drafted a given drawing with AutoCAD in a preset time.

\section{Analysis and results}

Cognitive style characteristics of the sample group

The WA ratios of the total sample ranged from 0.56 to 2.97 with a mean of 1.38 (SD = 0.57 ) and a median of 1.26. The VI ratios ranged from 0.83 to 1.63 with a mean of 1.07 $(\mathrm{SD}=0.18)$ and a median of 1.04 . There were $30(65 \%)$ Analytics, $10(22 \%)$ Wholists, and $6(13 \%)$ Intermediates. It was observed that on the WA dimension, the sample was predominantly Analytic. Previous research also reported that architecture students were Analytic-oriented (Roberts 2006; Bergum 1977). This result was probably due to the university admissions process. In Turkey, the students are admitted to university education through a general multiple choice test exam which is possibly filtering out the Wholists. On the VI dimension, the sample was more evenly distributed. There were 19 (41\%) Verbalisers, 14 (31\%) Bimodals, and 13 (28\%) Imagers.

Reliability and validity of measures

The correlation between the two cognitive style dimensions was -0.025 indicating the orthogonality of the two dimensions (Riding and Cheema 1991). Inter-rater reliabilities of 
Table 1 Inter-rater reliabilities of performance evaluation

\begin{tabular}{lll}
\hline Evaluation category & Stage & Inter-rater reliability \\
\hline Creativity & Stage 1 & 0.66 \\
& Stage 2 & 0.73 \\
Stage 3 & 0.78 \\
Technical quality & Stage 1 & 0.76 \\
& Stage 2 & 0.79 \\
& Stage 3 & 0.81 \\
\hline
\end{tabular}

the judges were calculated for the creativity and the technical quality scores in the three stages. The reliability levels were above the acceptable level of 0.70 recognized by Amabile (1996) (Table 1).

Relationships between cognitive styles and design performance

The data was initially analysed using the raw CSA ratios as recommended by Peterson et al. (2002). A significant positive correlation was found between the VI ratios and the average creativity scores $(r=0.32, p<0.05)$. The correlation between the WA ratios and the average creativity scores was not statistically significant $(r=0.14)$. The data suggested that the average technical quality scores were independent from WA $(r=0.06)$ and VI $(r=$ $0.1)$ ratios.

Then, the sample was grouped by the cognitive style categories defined in the CSA administration documentation (Riding 1991), Analytic-Intermediate-Wholist in one dimension and Imager-Bimodal-Verbaliser on the other. The analysis of variance (ANOVA) tests were conducted in order to find out if the cognitive styles had any effect on the average creativity and technical quality performance scores at the end of the process. The ANOVA indicated that there were statistically significant mean creativity score differences only on the VI dimension of CSA $(F=3.95, p=0.027)$ (Table 2). No such

Table 2 Mean creativity scores on the VI dimension

\begin{tabular}{lllll}
\hline VI & $\begin{array}{l}\text { Stage 1 creativity } \\
\text { mean }(\mathrm{SD})\end{array}$ & $\begin{array}{l}\text { Stage 2 creativity } \\
\text { mean }(\mathrm{SD})\end{array}$ & $\begin{array}{l}\text { Stage 3 creativity } \\
\text { mean }(\mathrm{SD})\end{array}$ & $\begin{array}{l}\text { Overall creativity } \\
\text { mean }(\mathrm{SD})\end{array}$ \\
\hline Imager & $2.61(0.49)$ & $2.61(0.75)$ & $2.97(0.78)$ & $2.73(0.53)$ \\
Bimodal & $2.48(0.61)$ & $2.57(0.61)$ & $2.90(0.83)$ & $2.63(0.56)$ \\
Verbaliser & $2.27(0.43)$ & $2.17(0.30)$ & $2.49(0.60)$ & $2.28(0.39)$ \\
Total & $2.45(0.52)$ & $2.44(0.60)$ & $2.75(0.75)$ & $2.51(0.51)$ \\
\hline
\end{tabular}

Table 3 Mean creativity scores on the WA dimension

\begin{tabular}{lllll}
\hline WA & $\begin{array}{l}\text { Stage 1 creativity } \\
\text { mean (SD) }\end{array}$ & $\begin{array}{l}\text { Stage 2 creativity } \\
\text { mean (SD) }\end{array}$ & $\begin{array}{l}\text { Stage 3 creativity } \\
\text { mean (SD) }\end{array}$ & $\begin{array}{l}\text { Overall creativity } \\
\text { mean (SD) }\end{array}$ \\
\hline Analytic & $2.39(0.46)$ & $2.33(0.52)$ & $2.82(0.75)$ & $2.47(0.48)$ \\
Intermediate & $2.72(0.77)$ & $3.00(0.94)$ & $3.00(0.84)$ & $2.89(0.80)$ \\
Wholist & $2.40(0.49)$ & $2.38(0.36)$ & $2.47(0.69)$ & $2.42(0.37)$ \\
Total & $2.45(0.52)$ & $2.44(0.60)$ & $2.75(0.75)$ & $2.51(0.51)$ \\
\hline
\end{tabular}


Table 4 Mean technical quality scores on the VI dimension

\begin{tabular}{lllll}
\hline VI & $\begin{array}{l}\text { Stage 1 technical } \\
\text { quality mean }(\mathrm{SD})\end{array}$ & $\begin{array}{l}\text { Stage 2 technical } \\
\text { quality mean }(\mathrm{SD})\end{array}$ & $\begin{array}{l}\text { Stage 3 technical } \\
\text { quality mean }(\mathrm{SD})\end{array}$ & $\begin{array}{l}\text { Overall technical } \\
\text { quality mean }(\mathrm{SD})\end{array}$ \\
\hline Imager & $2.51(0.44)$ & $2.46(0.48)$ & $2.85(0.74)$ & $2.61(0.43)$ \\
Bimodal & $2.43(0.62)$ & $2.81(0.95)$ & $2.95(0.98)$ & $2.73(0.70)$ \\
Verbaliser & $2.39(0.56)$ & $2.72(1.04)$ & $2.71(0.91)$ & $2.55(0.74)$ \\
Total & $2.44(0.53)$ & $2.66(0.87)$ & $2.80(0.88)$ & $2.61(0.64)$ \\
\hline
\end{tabular}

Table 5 Mean technical quality scores on the WA dimension

\begin{tabular}{lllll}
\hline WA & $\begin{array}{l}\text { Stage 1 technical } \\
\text { quality mean (SD) }\end{array}$ & $\begin{array}{l}\text { Stage 2 technical } \\
\text { quality mean }(\mathrm{SD})\end{array}$ & $\begin{array}{l}\text { Stage 3 technical } \\
\text { quality mean }(\mathrm{SD})\end{array}$ & $\begin{array}{l}\text { Overall technical } \\
\text { quality mean }(\mathrm{SD})\end{array}$ \\
\hline Analytic & $2.40(0.50)$ & $2.73(0.94)$ & $2.83(0.89)$ & $2.62(0.67)$ \\
Intermediate & $2.89(0.45)$ & $2.67(0.70)$ & $2.89(1.11)$ & $2.81(0.69)$ \\
Wholist & $2.27(0.58)$ & $2.50(0.82)$ & $2.77(0.75)$ & $2.51(0.57)$ \\
Total & $2.44(0.53)$ & $2.66(0.87)$ & $2.80(0.88)$ & $2.61(0.64)$ \\
\hline
\end{tabular}

difference was observed on the WA dimension (Table 3) or in the mean technical quality scores across the cognitive style groups (Tables 4 and 5). The Bonferroni test indicated that the mean creativity scores of Imagers were significantly higher than that of Verbalisers $(p$ $<0.05$ ), but no other significant difference was found.

\section{Cognitive styles and performance in different stages of the design process}

The effects of cognitive styles on creative performance were also analyzed in relation to the three stages of the design process. The analysis of variance tests for repeated measures did not indicate any evidence that the interaction between cognitive styles and performance scores changed over the stages $(F=1.66, p=0.18)$. Although the estimated marginal creativity means indicated some slight differences in the progression of different cognitive style groups (Figs. 3 and 4), the relation between cognitive styles and creativity scores remained similar through the stages.

Due to the nature of the educational process, it was expected that performance scores would increase from stage 1 to stage 3 . Paired samples $t$-tests showed that mean creativity scores in stage 3 were significantly higher than that of stage $1(t=-2.09, p=0.043)$ and stage $2(t=-4.16, p<0.001)$. However, mean difference between creativity scores of stage 1 and stage 2 was not significant. The same tests were applied in the technical quality scores and it was found that although there was a statistically significant increase between the mean technical quality scores of stage 1 and stage $3(t=-2.33, p=0.024)$, the mean differences at the consecutive stages (stage 1-stage 2 and stage 2 -stage 3 ) were not significant.

\section{Cognitive styles and drafting performance}

In order to investigate the relationships between cognitive styles and drafting performance, Pearson correlation coefficients were calculated between the cognitive dimensions' raw scores and the drafting performance scores. A significant correlation was found between the VI raw scores and the drafting scores $(r=0.54, p<0.001)$, while the drafting scores 


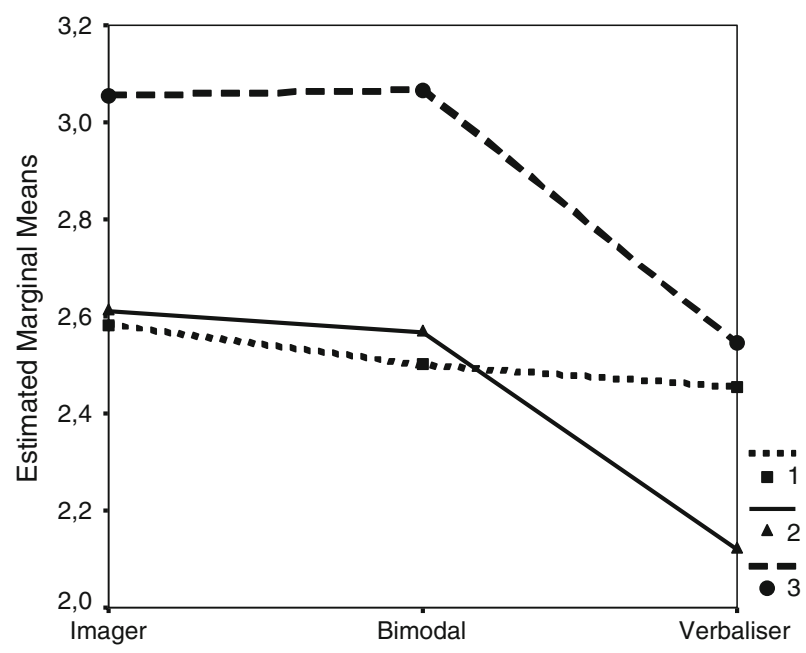

Fig. 3 The estimated marginal creativity means of the three VI cognitive styles through stages 1-3

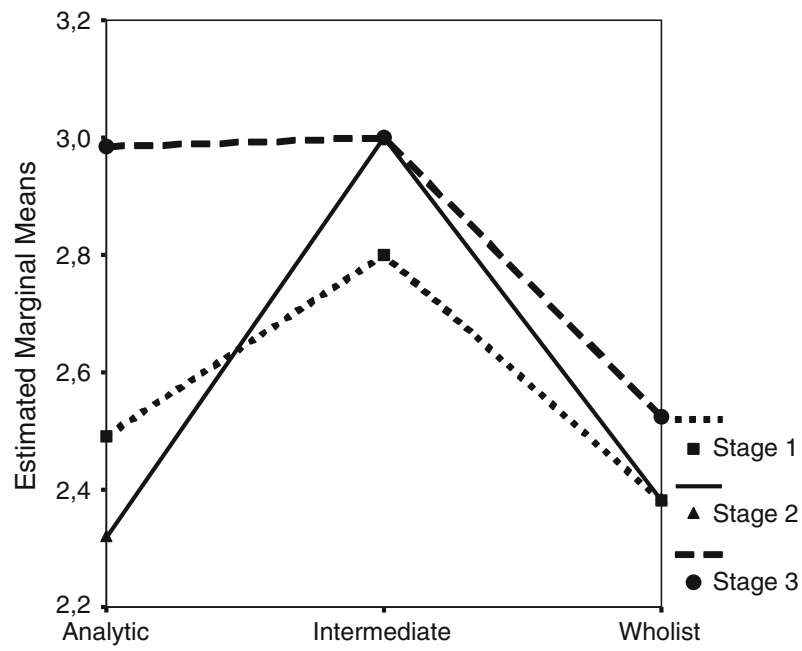

Fig. 4 The estimated marginal creativity means of the three WA cognitive styles through stages 1-3

seemed to be independent from the WA raw scores $(r=0.06, p=0.7)$. One-way Analysis of Variance tests also indicated a significant difference among the drafting scores of the students belonging to different cognitive styles on the VI dimension $(F=5.34, p=0.009)$. The Bonferroni test showed that the mean drafting scores of Imagers were significantly higher than that of Verbalisers $(p=0.007)$. No other difference was significant (Table 6).

\section{Discussion and conclusions}

This study provided valuable insights into the effects of cognitive styles of design students in several stages of design development in digital media. On the VI dimension, Imagers 
Table 6 Mean drafting performance scores on the WA and VI dimensions

\begin{tabular}{llll}
\hline WA & Drafting score mean (SD) & VI & Drafting score mean (SD) \\
\hline Analytic & $79.33(10.90)$ & Imager & $88.53(11.36)$ \\
Intermediate & $90.83(13.96)$ & Bimodal & $78.89(7.94)$ \\
Wholist & $76.20(13.50)$ & Verbaliser & $75.34(13.28)$ \\
Total & & & $79.97(12.17)$ \\
\hline
\end{tabular}

outperformed Verbalisers in both the average creativity scores $(t=2.63 p=0.016)$ and the drafting scores $(t=3.01, p=0.005)$. The implications of this finding can be far-reaching. Although the importance of visual thinking in design was widely acknowledged in the literature, few studies empirically investigated representational issues in typical complex design problems (Goldschmidt and Smolkov 2006) and, to the best of the author's knowledge, this study is first to relate VI cognitive styles and performance in design in architectural education context. Oxman (2002) claimed that creative emergence in design was not accidental, but depended on recognition of visual shapes and images which she called "thinking with images." Our findings supported Oxman's theory and indicated that individuals who tended to "think with images" rather than to "think with words" were likely to be more creative in the design process. Oxman (2002) did not discuss the origins of individual differences in visual recognition but recommended research in the middle ground between psychology and design to enlighten terra incognita of the "thinking eye." The present study suggested that one of the factors affecting visual recognition processes in design might be VI cognitive styles. However, the results of this study should be interpreted carefully, since they are obtained from an educational design project which was largely based on individual creation. In real-life design projects, where designers have to negotiate with other designers and with the client, "visual" translation of the "verbal" brief is a core skill, and verbal work seems to be an integral part of all phases of design (Tomes et al. 1998). Thus, the relationships between VI cognitive styles and creativity in design requires further studies in different contexts considering additional variables such as team design, effects of design media, and nature of design problems.

In our study, the data suggested that Imagers' high creativity scores in the design tasks were partly due to their proficiencies in using the CAD tool. When the drafting performance scores were controlled, the correlation between the VI raw scores and the average creativity scores were not significant $(r=0.14, p=0.35)$. This suggests that at the early stages of design education, students are often limited by their capabilities of using design tools. Coyne (2002) also argued that the computer offers a wide range of alternatives in design, however, inexperience seems to limit the possibilities: "If you only know how to draw a box, your building will be a box, and if you know how to design anything on the computer you can design anything" (qtd. in Coyne 2002). Thus, this study could also be expanded by comparing expert and novice designers in order to reveal whether the relationship between VI cognitive styles and performance in drafting and design tasks are moderated by experience or not.

On the WA dimension, there was no statistically significant difference among the success levels of cognitive style groups. In a way, this finding supported Kvan and Yunyan (2005) and Roberts (2006) who concluded that architectural design studios could encompass a wide range of learning/cognitive styles. In an earlier study, Demirbas and Demirkan (2003) found significant differences among the performance levels of learning style groups in a relatively simple and well-defined architectural design project. Both Kvan 
and Yunyan (2005) and Roberts (2006) compared their works with that of Demirbas and Demirkan (2003) and argued that architectural design studio environments, especially when design problems are complex and ill-defined, enabled students develop learning strategies that best suited their styles and as a result all style groups attained similar results. The design project utilized in this study was as complex and ill-defined as is common at sophomore level architectural design studios; thus, this conclusion seems to be valid also for our case. It should be noted that Kvan and Yunyan (2005) and Demirbas and Demirkan (2003) utilized Kolb's Learning Style Inventory and addressed learning styles construct; while, Roberts' study (2006) incorporated the WA dimension of CSA.

Besides the type of design problem, the way all the learning process structured, presented and managed should be considered while analyzing the relationships between cognitive styles and performance (Riding 2000a). Roberts (2006) explained that the higher success levels of Analytic students at the first year might be due to the tight framework imposed by the first year studios. He discussed that students' project work was fragmented and sequential in the first year which favoured Analytic students. At the later years, however, the projects were more complex and the studio programmes were less strict and according to Roberts (2006), these enabled Wholist students to flourish. Similarly, Atkinson (1998) investigated the relationship between pupils' cognitive styles, as measured by CSA, and performance in GCSE technology examination project work. She found that Analytic pupils whether they were Imagers or Verbalisers tended to attain better results in design tasks. Atkinson (1998) attributed this finding to the fragmented nature of the design process. However, the design program utilized in the current study was a typical example of the programs that are followed in sophomore level architectural design studios; and it neither imposed a sequential process nor split the process into clearly defined small tasks. Thus, this flexibility might have provided equal opportunities for Analytic and Wholist students for developing appropriate strategies deemed to be consonant with their cognitive styles.

At the beginning of the study, it was hypothesized that Analytic cognitive style might be better suited to the requirements of computer aided drafting and design. The data did not provide any evidence to support this argument. On the WA dimension, no statistically significant difference was found among the design and drafting performance scores of cognitive style groups. This may be due to the current status of CAD in design education. Riding (1997) explained that cognitive style was likely to be critical where the learner was under pressure, because, relative to ability, etc. the task was difficult. Nowadays, students begin university education with considerable computer experience and they experience little difficulty in introductory CAD courses (Pektas 2007; Mark et al. 2003). The high mean drafting performance scores of the subjects in this study $(X=79.97, \mathrm{SD}=12.17)$ supported this argument. Furthermore, an empirical study showed that design students' attitudes toward computers were highly positive, even more positive than that of their instructors (Pektas and Erkip 2006). At the very beginnings of the introduction of first commercial CAD tools, Cross (1985) suggested a mismatch between the predominantly appositional (holistic, non-verbal, and imaginative) cognitive styles of designers and the propositional (analytic, serialistic, and verbal) style of computers. He claimed that the problem of CAD education was to devise flexible systems which could provide each learner enough freedom to approach the design problem in her/his own cognitive style; otherwise, only students with a certain cognitive style would find CAD systems genial. An empirical study dated back to the same period (Guster 1986) supported this argument and reported that field-independent (Analytic) learners performed better in mechanical drafting tasks compared to their field-dependent (Wholist) counterparts. It seems that the 
widespread penetration of computers into the design fields and into the society at large as well as the development of user-friendly computer applications enabled design students to attain similar levels of success in computer aided drafting and design tasks independent from their positions on the WA spectrum. However, the scope and the nature of CAD tasks should be carefully considered in this respect. Nowadays, CAD applications involve many different representations of design knowledge from basic building geometry to 3D parametric modelling or simulation; and different applications may favour certain cognitive styles. This study utilized only 2D drafting oriented software. Thus, further research should be conducted in order to provide insights into the relationships between cognitive styles and performance in a variety of CAD tasks. Moreover, subjects' performance can be assessed on multiple tasks of increasing complexity to control effects of task difficulty.

Educational implications of the findings of this study could be more significant, if similar results were replicated in larger samples. However, this study suggested that monitoring cognitive styles of design students deserved further attention and might facilitate for improving teaching strategies and course designs.

Acknowledgements This research was funded by Bilkent University, Faculty Research Development Grant. The author would like to thank the judges and the students who contributed to the study.

\section{References}

Amabile, T. (1996). Creativity in context. Westview: Boulder.

Archer, L. B. (1984). Whatever became of design methodology. In N. Cross (Ed.), Developments in design methodology (pp. 347-349). Chichester: Wiley.

Armstrong, S. (2000). The influence of individual cognitive style on performance in management education. Educational Psychology, 20, 323-339.

Atkinson, S. (1998). Cognitive style in the context of design and technology project work. Educational Psychology, 18, 83-194.

Atkinson, S. (2006). Factors influencing successful achievement in contrasting design and technology activities in higher education. International Journal of Technology and Design Education, 16, 193-213.

Bergum, B. O. (1977). Undergraduate self perceptions of creativity and independence. Perceptual and Motor Skills, 44, 187-190.

Bilda, Z., \& Demirkan, H. (2003). An insight on designers' sketching activities in traditional versus digital media. Design Studies, 24, 27-50.

Christiaans, H. H. C. M. (2002). Creativity as a design criterion. Creativity Research Journal, 14, 41-54.

Coyne, R. (2002). Design devices: digital drawing and the pursuit of difference. Design Studies, 23, 263-286.

Cross, N. (1985). Styles of learning, designing and computing. Design Studies, 6, 157-162.

Cross, N. (1990). The nature and nurture of design ability. Design Studies, 11, 127-140.

Cross, N. (1993). A history of design methodology. In M. J. De Vries, N. Cross, \& D. P. Grant (Eds.), Design methodology and relationships with science. London: Kluwer.

Cross, N. (2004). Expertise in design: An overview. Design Studies, 25, 427-441.

Curry, L. (1983). An organisation of learning styles and constructs. Eric Document, 235, 185.

Demirbas, O. O., \& Demirkan, H. (2003). Focus on architectural design process through learning styles. Design Studies, 24, 437-456.

Finke, R. (1990). Creative imagery: discoveries and inventions in visualization. Hillsdale: Erlbaum.

Garcia, R. R., Santos, R. G., Quiros, J. S., \& Penin, P. I. A. (2005). Present state of CAD teaching in Spanish universities. Computers and Education, 44, 201-215.

Goldschmidt, G., \& Smolkov, M. (2006). Variances in the impact of visual stimuli on design problem solving performance. Design Studies, 27, 549-569.

Guster, D. (1986). Cognitive style and drafting performance. Journal of Vocational Education Research, 11, $25-40$.

Hamade, R. F., Artail, H. A., \& Jaber, M. Y. (2007). Evaluating the learning process of mechanical CAD students. Computers and Education, 49, 640-661.

Hudson, L. (1966). Contrary imaginations. Harmondsworth: Penguin. 
Jeffries, K. K. (2007). Diagnosing the creativity of designers: individual feedback within mass higher education. Design Studies, 28, 485-497.

Jonson, B. (2005). Design ideation: the conceptual sketch in the digital age. Design Studies, 26, 613-624.

Kvan, T., \& Yunyan, J. (2005). Students' learning styles and their correlation with performance in architectural design studio. Design Studies, 26, 19-34.

Lawson, B. (1997). How designers think: the design process demystified. Oxford: Architectural Press.

Mark, E., Martens, B., \& Oxman, R. (2003). Preliminary stages of CAAD education. Automation in Construction, 12, 661-670.

Martinsen, O., \& Kaufmann, G. (2000). The assimilator-explorer cognitive styles and their relationship to affective-motivational orientations and cognitive performances. In R. Riding \& S. Rayner (Eds.), International perspectives on individual differences: vol 1 cognitive styles (pp. 3-39). Stamford: Ablex.

Meneely, J., \& Portillo, M. (2005). The adaptable mind in design: Relating personality, cognitive style, and creative performance. Creativity Research Journal, 17, 155-166.

Messick, S. (1984). The nature of cognitive style: problems and promise in educational practice. Educational Psychologist, 19, 59-74.

Miller, A. (1987). Cognitive styles: an integrated model. Educational Psychology, 7, 251-268.

Oxman, R. (2002). The thinking eye: Visual re-cognition in design emergence. Design Studies, 23, $135-164$.

Paivio, A. (1971). Imagery and verbal processes. Holt, Rinehart \& Winston: New York.

Pask, G. (1972). A fresh look at cognition and the individual. International Journal of Man-Machine Studies, 4, 211-216.

Pektas, S. T. (2007). A structured analysis of CAAD education. Open House International, 32(2), 46-54.

Pektas, S. T., \& Erkip, F. (2006). Attitudes of design students toward computer usage in design. International Journal of Technology and Design Education, 16(1), 79-95.

Peterson, E. R., Deary, I. J., \& Austin, E. J. (2002). The reliability of Riding's Cognitive Styles Analysis test. Personality and Individual Differences, 34, 881-891.

Richardson, A. (1977). Verbaliser-visualiser: A cognitive style dimension. Journal of Mental Imagery, 1, $109-126$.

Riding, R. (1991). Cognitive styles analysis. Birmingham: Learning and Training Technology.

Riding, R. (1997). On the nature of cognitive style. Educational Psychology, 17, 29-49.

Riding, R. (2000a). Cognitive style: a review. In R. Riding \& S. Rayner (Eds.), International perspectives on individual differences: vol 1 cognitive styles (pp. 315-344). Stamford: Ablex.

Riding, R. (2000b). Cognitive style: a strategic approach for advancement. In R. Riding \& S. Rayner (Eds.), International perspectives on individual differences: vol 1 cognitive styles (pp. 365-377). Stamford: Ablex.

Riding, R., \& Cheema, I. (1991). Cognitive styles: An overview and integration. Educational Psychology, 11, 193-216.

Riding, R., \& Rayner, S. (1997). Towards a categorisation of cognitive styles and learning styles. Educational Psychology, 17, 5-29.

Riding, R., \& Rayner, S. (1998). Cognitive styles and learning strategies. London: David Fulton.

Roberts, A. (2006). Cognitive styles and student progression in architectural design education. Design Studies, 27, 167-181.

Schon, D. (1983). The reflective practitioner. New York: Basic Books.

Schon, D. (1985). The design studio: an exploration of its traditions and potentials. London: RIBA Publications.

Stones, C., \& Cassidy, T. (2007). Comparing synthesis strategies of novice graphic designers using digital and traditional design tools. Design Studies, 28, 59-72.

Tomes, A., Oates, C., \& Armstrong, P. (1998). Talking design: Negotiating the verbal-visual translation. Design Studies, 19, 127-142.

Tweed, C. (2001). The social context of CAAD in practice. Automation in Construction, 10, 617-629.

Witkin, H. A., Oltman, P., Raskin, E., \& Karp, S. (1971). A manual for embedded figures test. Palo Alto: CA Consulting Psychologists Press. 